\title{
QUALIDADE MICROBIOLÓGICA DE QUEIJO MINAS FRESCAL COMERCIALIZADO NA ZONA DA MATA MINEIRA
}

\section{Microbiological quality of Minas frescal cheese traded in Zona da Mata Mineira}

\author{
Iury Antônio de Souza ${ }^{l}$, Ana Cristina da Silva Giovannetti ${ }^{1}$, \\ Luiz Guilherme de Freitas Santos ${ }^{I}$, Scarlet Ohana da Silva Gandra ${ }^{l}$, \\ Maurilio Lopes Martins ${ }^{1 *}$, Alcinéia de Lemos Souza Ramos ${ }^{2}$
}

\section{RESUMO}

Este trabalho objetivou avaliar a qualidade microbiológica do queijo Minas frescal comercializado na Zona da Mata Mineira. As amostras foram coletadas em seis municípios: Juiz de Fora (33), Cataguases (7), Itamarati de Minas (4), Belmiro Braga (2), Bicas (2) e Rio Pomba (2), totalizando 50 marcas, sendo 43 de produção industrial e sete informais. As análises de $\mathrm{pH}$, atividade de água (Aw), coliformes a $35^{\circ} \mathrm{C}$ e a $45^{\circ} \mathrm{C}$, Escherichia coli, estafilococos coagulase positiva, Staphylococcus aureus, Listeria monocytogenes e Salmonella sp. foram realizadas entre outubro de 2015 e janeiro de 2016. Os valores de $\mathrm{pH}$ variaram entre 4,98 a 7,14 e a Aw entre 0,989 a 0,904 . Todas as amostras, independente da origem, apresentaram coliformes a $35^{\circ} \mathrm{C}$, com valores variando de $1,5 \times 10^{1}$ a $1,1 \times 10^{6} \mathrm{NMP} / \mathrm{g}$. Dentre as amostras, 20 (40\%) apresentaram Número Mais Provável acima do limite máximo estabelecido pela legislação para coliformes a $45^{\circ} \mathrm{C}$, sendo a média de $1,2 \times 10^{5} \mathrm{NMP} / \mathrm{g}$. A presença de E. coli foi confirmada em 16 amostras (32\%). As contagens de estafilococos coagulase positiva também foram acima do limite aceito em $16(32 \%)$ amostras e $10(20 \%)$ continham S. aureus. Não foi constatada presença de L. monocytogenes, entretanto, Salmonella sp. foi confirmada em 20 amostras (40\%). Constatou-se que, apenas 11 amostras (22\%), estavam em conformidade com a legislação brasileira. Portanto, o queijo Minas frescal comercializado na região apresentou baixa qualidade

1 Instituto Federal de Educação, Ciência e Tecnologia do Sudeste de Minas Gerais, Câmpus Rio Pomba, Av. Dr. José Sebastião da Paixão, s/nº, Bairro Lindo Vale, 36180-000, Rio Pomba, MG, Brasil. E-mail: maurilio.martins@ifsudestemg.edu.br

2 Universidade Federal de Lavras, Lavras, MG, Brasil.

* Autor para correspondência.

Recebido / Received: 29/07/2017

Aprovado / Approved: 11/12/2017 
microbiológica, sugerindo deficiências no processamento, transporte, armazenamento e/ou comercialização e perigo à saúde humana.

Palavras-chave: queijo fresco, Escherichia coli, estafilococos coagulase positiva, Listeria monocytogenes, Salmonella sp., segurança dos alimentos.

\begin{abstract}
This study aimed to evaluate the microbiological quality of Minas frescal cheese traded in Zona da Mata Mineira, Brazil. The samples were collected at six cities: Juiz de Fora (33), Cataguases (7), Itamarati de Minas (4), Belmiro Braga (2), Bicas (2) and Rio Pomba (2), totaling 50 brands, being 43 of industrial production and seven informal. Analyses of $\mathrm{pH}$, Aw, coliforms at $35^{\circ} \mathrm{C}$ and $45^{\circ} \mathrm{C}$, Escherichia coli, coagulase positive staphylococci, Staphylococcus aureus, Listeria monocytogenes and Salmonella sp. were held in the period from October 2015 to January 2016. The $\mathrm{pH}$ values ranged from 4,98 to 7,14, and Aw from 0,989 to 0,904. All samples, regardless of origin, showed coliform at $35^{\circ} \mathrm{C}$, with values ranging between $1,5 \times 10^{1}$ a $1,1 \times 10^{6} \mathrm{NMP} / \mathrm{g}$. Among samples, 20 (40\%) showed the Most Probable Number of coliforms at $45^{\circ} \mathrm{C}$ above the maximum limit set by Brazilian law, with a rate of 1,2 x $10^{5} \mathrm{MPN} / \mathrm{g}$. The presence of $E$. col $i$ was confirmed in $16(32 \%)$ samples. Counts of coagulase positive staphylococci were also above the limit accepted in $16(32 \%)$ samples, and $10(20 \%)$ presented $S$. aureus. It was not detected L. monocytogenes in any sample, however, Salmonella sp. was confirmed in $20(40 \%)$ samples. It was verified that only $11(22 \%)$ samples were in accordance with Brazilian legislation. Therefore, the Minas frescal cheese commercialized in the region presented low microbiological quality, suggesting deficiencies in the processing, transport, storage and/or commercialization and danger to human health.
\end{abstract}

Keywords: fresh cheese, Escherichia coli, coagulase positive staphylococci, Listeria monocytogenes, Salmonella sp., food safety.

\section{INTRODUÇÃO}

Entende-se por queijo Minas frescal o queijo fresco obtido por coagulação enzimática do leite com coalho e/ou outras enzimas coagulantes apropriadas, complementada ou não com ação de bactérias lácticas específicas. O queijo Minas frescal é um queijo semi-gordo, de muito alta umidade, a ser consumido fresco, de acordo com a classificação estabelecida no Regulamento Técnico de Identidade e Qualidade de Queijos (BRASIL, 2004).

Este produto é um dos queijos não curados mais populares e produzidos no Brasil, apresentando um expressivo valor socioeconômico e cultural. É considerado um alimento de fácil produção, elevado consumo, porém, de consumo imediato e curta vida de prateleira (NASCIMENTO et al., 2008; VISOTTO et al., 2011). É caracterizado por sua massa branca de consistência macia, sabor suave ou levemente ácido (BRASIL, 2004; RIBEIRO et al., 2009).

A ocorrência de microrganismos patogênicos em queijo Minas frescal tem sido demonstrada por inúmeras pesquisas ao longo dos últimos anos, sendo evidenciado um quadro desfavorável da qualidade deste alimento independente da sua origem de 
fabricação (LOGUERCIO; ALEIXO, 2001; SALOTTI et al., 2006; BRITO et al., 2008; MARTINS; REIS, 2012).

O grande número de amostras não condizentes com os padrões microbiológicos favorece a ocorrência de doenças veiculadas por alimentos e ressalta a importância do cuidado higiênico-sanitário com a sua manipulação e controle de qualidade, matériaprima e processo de fabricação (ABRAHÃO et al., 2008; BORGES et al., 2008; SENGER; BIZANI, 2011).

Existem diferentes fatores que podem afetar a capacidade de sobrevivência e/ou multiplicação de microrganismos em um alimento. Entre estes destacam-se os que se relacionam com as características do próprio alimento como, por exemplo, $\mathrm{pH}$, acidez, atividade de água (Aw), presença de nutrientes, entre outros, sendo chamados de fatores intrínsecos (AZEREDO et al., 2012).

Diante disso, objetivou-se avaliar a qualidade microbiológica de queijo Minas frescal quanto ao Número Mais Provável de coliformes a $30{ }^{\circ} \mathrm{C}$ e $45{ }^{\circ} \mathrm{C}$, contagem de estafilococos coagulasse positiva e presença de Staphylococcus aureus, Escherichia coli, Listeria monocytogenes e Salmonella sp., de modo a se avaliar a conformidade dos mesmos com a legislação vigente.

\section{MATERIAL E MÉTODOS}

\section{Amostragem}

As amostras foram coletadas no período de outubro de 2015 a janeiro de 2016 em seis municípios da Zona da Mata Mineira, totalizando 50 marcas, conforme Tabela 1. Destas, 43 eram provenientes de produção industrial e comercializadas em estabelecimentos comerciais, seis de produção artesanal e vendidas diretamente pelo produtor e uma amostra era de origem artesanal e comercializada por estabelecimento comercial. As amostras de produção industrial apresentavam fiscalização por um dos órgãos de inspeção (SIF ou SIM), diferentemente das amostras de fabricação informal, que não passavam por nenhum tipo de fiscalização. Além disso, cinco foram categorizadas como light, uma sem lactose e sete não apresentavam embalagem, sendo comercializadas em saquinhos de polietileno de baixa densidade.

Após a coleta, as amostras eram acondicionadas em bolsas térmicas previamente sanitizadas com álcool $70 \%$ e climatizadas a $4,0{ }^{\circ} \mathrm{C}$ com gelo reciclável e transportadas até o laboratório de Microbiologia de Alimentos onde eram armazenadas, por no máximo três dias, a $4,0^{\circ} \mathrm{C}$ até o momento da análise.

Previamente às análises, as amostras de

Tabela 1 - Número de amostras de queijo Minas frescal, por cidade, submetidas a avaliação microbiológica

\begin{tabular}{cccc}
\hline Município & $\begin{array}{c}\text { Número } \\
\text { de amostras }\end{array}$ & Industrial & Artesanal \\
\hline Juiz de Fora & 33 & 33 & - \\
Cataguases & 7 & 6 & 1 \\
Itamarati de Minas & 4 & - & 4 \\
Belmiro Braga & 2 & - & 2 \\
Bicas & 2 & 2 & - \\
Rio Pomba & 2 & 2 & - \\
Total & 50 & 43 & 7 \\
\hline
\end{tabular}


queijo Minas frescal eram, assepticamente, totalmente maceradas para a posterior retirada de alíquotas para a caracterização de $\mathrm{pH}, \mathrm{Aw}$ e microbiológica.

\section{Determinação de $\mathrm{pH}$ e de atividade de água (Aw)}

A determinação de $\mathrm{pH}$ foi efetuada conforme Sakuma et al. (2008), sendo pesadas 10 gramas de cada amostra já macerada e transferidas para béqueres distintos de $100 \mathrm{~mL}$ contendo água destilada $(50 \mathrm{~mL})$ a $40{ }^{\circ} \mathrm{C}$. A fração pesada foi homogeneizada, e, em seguida, o eletrodo do potenciômetro (Modelo $\mathrm{mPa} 210$ ), calibrado com soluções tampão com $\mathrm{pH}$ 4,0 e 7,0 foi introduzido para a realização da leitura. Ao final de cada análise, o eletrodo foi lavado com água destilada e seco com papel de textura macia. A determinação da atividade de água das amostras foi realizada por meio de leitura direta no medidor digital Aqualab (Decagon Devices Aqualab Lite).

\section{Análises microbiológicas}

Para as análises microbiológicas, 25 gramas de cada amostra macerada foram pesadas e acrescidas de $225 \mathrm{~mL}$ de água peptonada $1 \%$ e então homogeneizadas em Stomacher (Marconi MA 440/CF), obtendo-se a diluição $10^{-1}$.

\section{Determinação do Número Mais Provável de coliformes e identificação de $E$.coli}

A determinação do Número Mais Provável de coliformes a $35{ }^{\circ} \mathrm{C}$ e a $45{ }^{\circ} \mathrm{C}$ foi realizada conforme descrito por Kornacki; Johnson (2001) utilizando-se no teste presuntivo Caldo Lauril Sulfato Triptose (LST - Micromed) e, posteriormente, Caldo Verde Brilhante Bile 2\% (VB - Himedia) e Caldo E. coli (EC - Himedia), respectivamente. De cada tubo contendo caldo EC com produção de gás, foi estriada uma alçada em ágar
Eosina Azul de Metileno (EMB - Himedia). As placas foram incubadas a $35^{\circ} \mathrm{C}$ por 24 horas. Após o crescimento, cinco colônias típicas (negras e com brilho verde metálico) ou atípicas das placas com ágar EMB foram selecionadas, ativadas em Ágar Padrão para Contagem (PCA - Himedia) e a partir destas foi realizado o teste IMViC (Indol, Vermelho de Metila, Voges-Proskauer e Citrato), sendo confirmadas como E. coli, as colônias positivas ou negativas no teste Indol, positivas no teste de Vermelho de Metila e negativas no teste de Vogues Proskauer e de Citrato (KORNACKI; JOHNSON, 2001).

\section{Contagem de estafilococos coagulase po- sitiva e determinação de $S$. aureus}

Esta análise foi realizada conforme Lancette; Bennett (2001) utilizando-se Ágar Baird Parker (BP - Himedia). As colônias típicas de $S$. aureus nesse meio são negras rodeadas por um halo opaco e um halo transparente, provenientes da precipitação da lecitina e proteólise, respectivamente. Foram selecionadas cinco colônias típicas e/ou atípicas para realização do teste de coagulase e determinação da contagem de estafilococos coagulase positiva. S. aureus foi confirmado por meio dos testes bioquímicos de coagulase, catalase e termonuclease.

\section{Isolamento e identificação de $L$. mo-} nocytogenes

Conforme Brasil (2003) e Hitchins et al. (2011), alíquotas de $25 \mathrm{~g}$ de amostras devidamente homogeneizadas foram submetidas ao enriquecimento seletivo primário em $225 \mathrm{~mL}$ de caldo Half-Fraser (Himedia), sendo incubadas a $30 \pm 1{ }^{\circ} \mathrm{C}$ por 24 horas. Em seguida, uma alíquota de $0,1 \mathrm{~mL}$ da cultura obtida no enriquecimento primário foi transferida para tubo contendo $10 \mathrm{~mL}$ de caldo Fraser (Himedia), representando o enriquecimento secundário. Os tubos foram 
incubados a $30 \pm 1{ }^{\circ} \mathrm{C}$ por 24 horas. A partir do segundo enriquecimento, foi inoculada uma alçada da cultura na superfície dos ágares Listeria Ottaviani e Agosti (ALOA - Fluka), Palcam (Acumedia) e Oxford (Himedia), sendo as placas incubadas a $30 \pm 1{ }^{\circ} \mathrm{C}$ por 24 a 48 horas. Após a incubação, cinco colônias típicas ou atípicas de cada amostra foram inoculadas em Ágar Tripticase de Soja Extrato de Levedura (TSA-YE - Micro Med) e as placas incubadas a $37 \pm 1{ }^{\circ} \mathrm{C}$ por 48 horas. Colônias típicas ou suspeitas em Ágar TSAYE foram estriadas neste ágar novamente, de modo a isolá-las e obter maior pureza, e as placas foram incubadas a $37 \pm 1{ }^{\circ} \mathrm{C}$ por 48 horas (BRASIL, 2003; HITCHINS et al., 2011). Para confirmação, as colônias foram submetidas às provas de catalase, coloração de Gram, vermelho de metila, Voges-Proskauer, motilidade típica e quando necessário à fermentação de xilose, manitol e raminose (RYSER; DONNELLY, 2001; BRASIL, 2003; HITCHINS et al., 2011).

\section{Isolamento e identificação de Salmonella spp.}

Uma porção de 25 gramas das amostras homogeneizadas foi transferida para um frasco estéril, no qual foi adicionado 225 $\mathrm{mL}$ de caldo de pré-enriquecimento (Caldo Lactosado), sendo a mistura homogeneizada em Stomacher (Marconi MA 440/CF). A mesma foi deixada em repouso por 1 hora a temperatura ambiente para a verificação do $\mathrm{pH}$ (ideal 6,8 $\pm 0,2$ ), e consequente ajuste do mesmo com hidróxido de sódio $(\mathrm{NaOH}) 1 \mathrm{M}$, se necessário. Posteriormente, a incubação foi feita a $35 \pm 2{ }^{\circ} \mathrm{C}$ por 24 horas (ANDREWS et al., 2007).

Após este período, realizou-se o enriquecimento seletivo, sendo transferidas alíquotas de $0,1 \mathrm{~mL}$ para tubos contendo $10 \mathrm{~mL}$ de caldo Rappaport Vassilidis (Micro Med) e $1 \mathrm{~mL}$ para tubos contendo $10 \mathrm{~mL}$ de caldo Tetrationato (Acumedia). Estes foram incu- bados a $42 \pm 2{ }^{\circ} \mathrm{C}$ por 24 horas e $35 \pm 2{ }^{\circ} \mathrm{C}$ por 24 horas, respectivamente.

Posteriormente, os tubos de enriquecimento seletivo foram agitados em vortex e uma alçada de cada um foi estriada em placas contendo Ágar Hektoen (HE - Acumedia), Ágar Bismuto Sulfito (BS - Himedia) e Ágar Xilose Lisina Desoxicolato (XLD - Fluka), que foram incubadas a $35 \pm 2{ }^{\circ} \mathrm{C}$ por 24 horas para a posterior observação das colônias. Cinco colônias típicas e/ou atípicas de cada amostra foram selecionadas e submetidas as provas bioquímicas e sorológicas conforme descrito por Andrews et al. (2001) e Andrews et al. (2007).

\section{RESULTADOS E DISCUSSÃO}

\section{pH e atividade de água (Aw) dos queijos}

Considerando esses parâmetros e suas respectivas referências para favorecimento da multiplicação de microrganismos, 94\% das amostras de queijo Minas frescal avaliadas apresentaram-se favoráveis para a presença de bactérias. Isto pode estar relacionado as elevadas contagens de coliformes a $45{ }^{\circ} \mathrm{C}$ e estafilococos coagulase positiva, além da presença de E. coli e Salmonella sp. em muitas amostras de queijos. Na Tabela 2, estão demonstrados as respectivas médias de $\mathrm{pH}$ e Aw considerando o tipo de produção das amostras de queijo Minas frescal.

Silva (2005) afirmou que a faixa de $\mathrm{pH}$ ideal para queijos Minas frescal está entre 5,0 a 5,3. Considerando estes valores, $96 \%(\mathrm{n}=$ 48) das amostras se encontravam acima da faixa recomendada. Apenas duas amostras de origem industrial apresentaram $\mathrm{pH}$ de 4,98 e 5,23 , valores abaixo do citado. É importante ressaltar que queijos com maiores valores de $\mathrm{pH}$, apresentam menor vida de prateleira, visto que $\mathrm{pH}$ mais próximo da neutralidade favorece a multiplicação de microrganismos.

Segundo Dias et al. (2016), a variação de $\mathrm{pH}$ dos queijos pode ocorrer devido ao 
Tabela 2 - Valores de pH e atividade de água (média \pm desvio padrão) das amostras de queijo Minas frescal

\begin{tabular}{cccc}
\hline Parâmetros & $\begin{array}{c}\text { Média Geral } \\
(\mathrm{n}=50)\end{array}$ & $\begin{array}{c}\text { Industrializados } \\
(\mathrm{n}=43)\end{array}$ & $\begin{array}{c}\text { Artesanais } \\
(\mathrm{n}=7)\end{array}$ \\
\hline $\mathrm{pH}$ & $6,18 \pm 0,564$ & $6,19 \pm 0,559$ & $6,17 \pm 0,640$ \\
$\mathrm{Aw}$ & $0,963 \pm 0,016$ & $0,963 \pm 0,016$ & $0,940 \pm 0,021$ \\
\hline
\end{tabular}

tempo e temperatura de armazenamento nos supermercados, que favorecem ou não a multiplicação microbiana e consequente deterioração do produto. Caso haja, por exemplo, grande presença de coliformes a $45^{\circ} \mathrm{C}$, principalmente $E$. coli, ocorrerá a fermentação da lactose e diminuição dos valores de $\mathrm{pH}$. Esta redução de $\mathrm{pH}$ nos queijos com a presença de E. coli, foi observada por Kousta et al. (2010) ao avaliarem o pH de sete marcas de queijo Minas frescal comercializados em São Paulo e constatarem que seis continham valores elevados de coliformes a $45^{\circ} \mathrm{C}$ e acentuada redução do $\mathrm{pH}$ aos 21 dias de armazenamento.

Constatou-se elevadas contagens de coliformes a $45^{\circ} \mathrm{C}$ e presença de $E$. coli em 16 marcas analisadas, o que pode ter refletido na acidificação dos queijos e na ampla faixa de variação de $\mathrm{pH}$ encontrada. Referente às amostras com presença de $E$. coli, a média de $\mathrm{pH}$ encontrada foi de $5,94 \pm 0,57$, podendo alterar-se com o período de armazenamento. Ressalta-se que contagem microbiana presente no queijo pode ocasionar alterações de sabor, aparência e odor.

Em relação a Aw, 98\% das amostras apresentaram valores acima de 0,91, sendo este o valor mínimo para a multiplicação da maioria das bactérias. Assim, considerando apenas este parâmetro, as elevadas contagens de microrganismos encontradas nas amostras de queijo Minas frescal avaliadas, podem ter sido favorecidas com a grande presença de água disponível para uso pelas bactérias, visto que água livre é necessária para o seu metabolismo.

\section{Qualidade microbiológica}

De acordo com a Portaria n. ${ }^{\circ}$ 146/1996 do Ministério da Agricultura Pecuária e Abastecimento (MAPA), o limite máximo considerado aceitável de coliformes totais em queijo de muito alta umidade é de $10^{3} \mathrm{NMP} / \mathrm{g}$ (BRASIL, 1996) no estabelecimento industrial. Coliformes a $30{ }^{\circ} \mathrm{C}$ são indicativos da falta de higiene na produção, principalmente se estes forem provenientes de uma produção informal com ausência de Boas Práticas de Fabricação (BPF) (BRASIL, 2001).

No presente estudo, as amostras, independente de sua origem, apresentaram contagens de coliformes a $30^{\circ} \mathrm{C}$ variando de 15 a $1,1 \times 10^{6} \mathrm{NMP} / \mathrm{g}$, com média geral de 189,5 $\mathrm{NMP} / \mathrm{g}$. Da mesma forma, Dias et al. (2016), ao avaliarem amostras de queijo Minas frescal comercializados na região Sul de Goiás, e Zonta et al. (2013), ao avaliarem amostras de queijo Minas frescal comercializados em Arapongas - PR, constataram que, as amostras, em sua totalidade, independente de sua origem, estavam em desacordo com o padrão estabelecido pela legislação para Coliformes a $30{ }^{\circ} \mathrm{C}$.

Das 50 amostras analisadas no presente trabalho, $20(40 \%)$ excederam o limite máximo preconizado pela legislação vigente $\left(5,0 \times 10^{2} \mathrm{NMP} / \mathrm{g}\right)$ para coliformes a $45^{\circ} \mathrm{C}$ (BRASIL, 2001). Dentre as amostras com Número Mais Provável acima do limite máximo, 15 são de fabricação industrial e cinco (5) artesanal. Percentual mais significativo $(80 \%)$ de amostras com contagens superiores a $10^{2} \mathrm{NMP} / \mathrm{g}$ de Coliformes a $45^{\circ} \mathrm{C}$ foi 
constatado em estudo realizado por Ferreira et al. (2011), ao avaliarem a qualidade microbiológica de queijo Minas frescal comercializado em feiras livres no município de Uberlândia - MG. Percentual menos expressivo (12\%) foi encontrado por Lombardi; Rezende (2014), ao avaliarem amostras também provenientes de Uberlândia - MG, entretanto, esses autores analisaram apenas amostras de fabricação industrial.

Após a conclusão do teste $\mathrm{IMViC}$, foi constatada a presença de E. coli em 16 amostras $(32 \%)$, sendo a maior incidência em amostras de produção artesanal. A ausência de BPF, contaminação cruzada, seja na produção artesanal ou industrial, deficiências na distribuição, associadas às más condições de armazenamento, favorecem a presença de microrganismos no queijo, podendo ter contribuído para o NMP de coliformes a $45^{\circ} \mathrm{C}$ e presença de $E$. coli nas amostras.

No estudo de Okura; Marin (2014), ao avaliarem a presença de $E$. coli em queijos Minas frescal provenientes do Sudoeste de Minas Gerais, foi constatado que 30\% das amostras provenientes de estabelecimentos credenciados no Serviço de Inspeção Federal (SIF) e $70 \%$ das amostras provenientes de estabelecimentos não credenciados no SIF estavam impróprias para consumo devido a presença de E. coli. Percentual expressivo $(70,8 \%)$ da presença de E. coli também foi evidenciado no estudo de Leite Júnior et al. (2013), ao avaliarem amostras de queijo Minas Frescal comercializadas na Zona da Mata e Campos das Vertentes de Minas Gerais.

A legislação vigente para queijo Minas frescal preconiza o limite máximo de $5,0 \times 10^{2}$ UFC/g para estafilococos coagulase positiva (BRASIL, 2001). Das amostras avaliadas neste trabalho, independente da origem de fabricação, 16 (32\%) apresentaram contagens acima do limite estabelecido para este grupo microbiano e $10(20 \%)$ apresentaram $S$. aureus. Percentual mais expressivo (78\%) deste grupo microbiano foi evidenciado por
Ferreira et al. (2010), ao analisarem amostras de queijo Minas frescal comercializadas na região do Triângulo Mineiro.

Menor percentual $(16,12 \%)$ de amostras com contagens de estafilococos coagulase positiva acima do preconizado pela legislação vigente foi evidenciado por Apolinário et al. (2014), ao avaliarem a qualidade microbiológica de queijos Minas frescal produzidos por diferentes laticínios do estado de Minas Gerais.

Diferentes estudos evidenciam a presença de $S$. aureus em produtos lácteos no Brasil (PINTO et al., 2011; MARTINS; REIS, 2012). Em queijos, a presença de $S$. aureus pode ser decorrente do quadro de mastite, contaminação cruzada pós-processamento por meio do manipulador, entre outros motivos, que podem variar de acordo com o processo produtivo (FAGUNDES et al., 2010).

A maior preocupação relacionada a S. aureus é a produção de enterotoxinas, quando o mesmo está em altas contagens nos alimentos, havendo a possibilidade da ocorrência de intoxicações (FERREIRA et al., 2010). A quantidade mínima de $S$. aureus para produção e detecção de enterotoxinas estafilocócicas é $10^{5}$ a $10^{6} \mathrm{UFC} / \mathrm{mL}$ ou g de alimento (WONG; BERGDOLL, 2002; BORGES et al., 2008; SANTANA et al., 2010). Considerando esse valor, todas as amostras deste estudo com presença de $S$. aureus possuíam contagens superiores, estando susceptíveis a presença de enterotoxinas.

A legislação brasileira preconiza ausência de L. monocytogenes em queijo Minas frescal (BRASIL, 2001). As amostras analisadas neste estudo estavam condizentes com a legislação. Da mesma forma, Leite Júnior et al. (2013), Visotto et al. (2011) e Pinto et al. (2011), constataram a ausência desta bactéria em seus estudos. A ausência ou baixa incidência de L. monocytogenes pode estar associada às elevadas contagens de outros microrganismos no produto devido a sua baixa capacidade de competição. 
Em contrapartida, Apolinário et al. (2014), ao analisarem amostras de queijo Minas frescal provenientes de dez laticínios do estado de Minas Gerais, constataram a presença desta bactéria em $9,6 \%$ das amostras. Percentual similar $(9,3 \%)$ foi evidenciando por Beltran et al. (2015), ao avaliarem amostras de queijo fresco mexicano.

Falhas no processo de pasteurização, contaminação cruzada, acúmulo de restos alimentares, ventilação e umidade do local de produção são fatores que propiciam a presença de L. monocytogenes em queijos e ambiente de processamento dos mesmos (KOUSTA et al., 2010; CARPENTIER; CERF, 2011; DIAS et al., 2012; LAMBERTZ et al., 2012). A colonização de refrigeradores na indústria é considerada um foco potencial de contaminação e possível formação de biofilme, favorecendo a persistência deste microrganismo nos alimentos (FOX et al., 2011).

Assim como para L. monocytogenes, a legislação vigente preconiza a ausência de Salmonella sp. nos alimentos (BRASIL, 2001). Entretanto, essa bactéria foi constatada em $20(40 \%)$ amostras avaliadas neste trabalho, indicando expressiva necessidade de aperfeiçoamentos no processamento, armazenamento e/ou distribuição, de modo a garantir a qualidade microbiológica dos queijos.

A presença de Salmonella spp. também foi evidenciada por Wolupeck et al. (2012) em 3,3\% das amostras de queijo Minas frescal avaliadas, as quais eram comercializadas em Curitiba - PR. Um percentual similar $(3,8 \%)$ foi verificado por Guzman-Hernandez et al. (2016) ao avaliarem queijos frescos mexicanos.

Diferentemente deste trabalho e dos estudos citados anteriormente, Callon et al. (2011), Pinto et al. (2011), Rodrigues et al. (2011), Visotto et al. (2011), Leite Júnior et al. (2013), Apolinário et al. (2014), Lombardi; Rezende (2014) e Dias et al. (2016) não detectaram Salmonella sp. em amostras de queijo Minas frescal comercializadas em diferentes regiões do Brasil.

\section{CONCLUSÃO}

A maior parte das amostras de queijo Minas frescal analisadas apresentaram baixa qualidade microbiológica e não conformidade com a legislação brasileira, devido às elevadas contagens de microrganismos indicadores, o que sugere deficiências no processamento, transporte, armazenamento e/ou comercialização. Fato que pode ser corroborado pelo $\mathrm{pH}$ e Aw das amostras. Além disso, patógenos como S. aureus e Salmonella sp. estiveram presentes em muitas amostras indicando perigo à saúde humana.

\section{AGRADECIMENTOS}

À Fundação de Amparo à Pesquisa de Minas Gerias (FAPEMIG), ao Instituto Federal do Sudeste de Minas Gerais, campus Rio Pomba e ao grupo PET Ciências Agrárias pelo apoio financeiro.

\section{REFERÊNCIAS}

ABRAHÃO, W. M. et al. Occurrence of Listeria monocytogenes in cheese and ice cream produced in the state of Paraná, Brazil. Revista Brasileira de Ciências Farmacêuticas, v. 44, n. 2, p. 289-296, 2008.

ANDREWS, W. H. et al. Salmonella. In: DOWNES, F. P.; ITO, K. Compendium of Methods for the Microbiological Examination of Foods. Washington, DC: American Public Health Association - APHA, 2001. p. 357-380.

ANDREWS, W. H. et al. Salmonella. In: FOOD AND DRUG ADMINISTRATION FDA. Bacteriological Analytical Manual Online. Silver Spring: Food and Drug 
Administration-FDA, 2007. Chapter 5. Disponível em: <http://www.fda.gov/Food/ ScienceResearch/LaboratoryMethods/ BacteriologicalAnalyticalManualBAM/ default.htm>. Acesso em: 20 jan. 2016.

APOLINÁRIO, T. C. C. et al. Avaliação da qualidade microbiológica de queijo Minas frescal produzido por laticínios do Estado de Minas Gerais. Revista do Instituto de Laticínios Cândido Tostes, v. 69, n. 6, p. 433-442, 2014.

AZEREDO, H. M. C. et al. Alterações microbiológicas em alimentos durante a estocagem. In: AZEREDO, H. M. C. Fundamentos de estabilidade de alimentos. Brasília: Embrapa, 2012. p. 15-38.

BELTRAN, M. S. et al. Prevalence and characterization of Listeria monocytogenes, Salmonella and Shiga toxin-producing Escherichia coli isolated from small Mexican retail markets of queso fresco. International Journal of Environmental Health Research, v. 25, n. 2, p. 140-148, 2015.

BORGES, M. F. et al. Staphylococcus enterotoxigênicos em leite e produtos lácteos, suas enterotoxinas e genes associados: revisão. Boletim do Centro de Pesquisa de Processamento de Alimentos, v. 26, n. 1, p. 70-86, 2008.

BRASIL. Agência Nacional de Vigilância Sanitária. RDC $n^{0} 12$, de 02 de janeiro de 2001. Aprova o Regulamento Técnico sobre padrões microbiológicos para alimentos. Diário Oficial da União, Brasília, 10 jan. 2001.

BRASIL. Ministério da Agricultura, Pecuária e Abastecimento. Instrução Normativa $n^{\circ}$ 04, de 01 de Março de 2004. Inclusão do termo Muito na expressão Alta Umidade nos itens 2.2 (Classificação), 4.2.3 (Requisitos Físico-Químicos) e 5.1 (Aditivos), no Regulamento Técnico para fixação de Identidade e Qualidade do queijo Minas frescal. Diário Oficial da União, Brasília, 05 mar. 2004.

BRASIL. Ministério da Agricultura, Pecuária e Abastecimento. Instrução Normativa $n^{\circ}$ 62, de 26 de Agosto de 2003. Oficializa os Métodos Analíticos Oficiais para Análises Microbiológicas para Controle de Produtos de Origem Animal e Água. Diário Oficial da União, Brasília, 18 set. 2003.

BRASIL. Ministério da Agricultura, Pecuária e Abastecimento. Portaria $n^{0} 146$ de 07 de março de 1996. Aprova o Regulamento Técnico de Identidade e Qualidade de Queijos. Diário Oficial da União, Brasília, 11 mar. 1996.

BRITO, J. R. F. et al. Retail Survey of Brazilian Milk and Minas Frescal Cheese and a Contaminated Dairy Plant To Establish Prevalence, Relatedness, and Sources of Listeria monocytogenes Isolates. Applied and Environmental Microbiology, v. 74, n. 15, p. 4954-4961, 2008.

CALLON, C. et al. Ripening conditions: a tool for the control of Listeria monocytogenes in uncooked pressed type cheese. Food Control, v. 22, n. 12, p. 1911-1919, 2011.

CARPENTIER, B.; CERF, O. Review-persistence of Listeria monocytogenes in food industry equipment and premises. International Journal of Food Microbiology, v. 145 , n. 1, p. 1-8, 2011

DIAS, B. F. et al. Qualidade microbiológica e físico-química de queijo Minas frescal artesanal e industrial. Revista de Agricultura Neotropical, v. 3, n. 3, p. 57-64, 2016.

DIAS, M. A. C. et al. On the implementation of good manufacturing practices in a 
small processing unity of Mozzarella cheese in Brazil. Food Control, v. 24, n. 1, p. 199205, 2012.

FAGUNDES, H. et al. Occurrence of Staphylococcus aureus in raw milk produced in dairy farms in São Paulo State, Brazil. Brazilian Journal of Microbiology, v. 41, n. 2, p. 376-380, 2010.

FERREIRA, G. B. et al. Pesquisa de Staphylococcus aureus em queijos tipo "Minas frescal" comercializados na região do Triângulo Mineiro. Revista Baiana de Saúde Pública, v. 34, n. 3, p. 575-589, 2010.

FERREIRA, R. M. et al. Quantificação de coliformes totais e termotolerantes em queijo Minas Frescal artesanal. Publicações em Medicina Veterinária e Zootecnia, v. 5, n. 5, p. 1019-1026, 2011.

FOX, E. et al. Listeria monocytogenes in Irish Farmhouse cheese processing environments. International Journal of Food Microbiology, v. 145, n. 1, p. 39-45, 2011.

GUZMAN-HERNANDEZ, R. et al. Mexicanun pasteurised fresh cheeses are contaminated with Salmonella spp., non-O157 Shiga toxin producing Escherichia coli and potential uropathogenic E. coli strains: A public health risk. International Journal of Food Microbiology, v. 237, p. 10-16, 2016.

HITCHINS, A. D. et al. Detection and Enumeration of Listeria monocytogene in Foods. In: FOOD AND DRUG ADMINISTRATION - FDA. Bacteriological Analytical Manual Online. Silver Spring: Food and Drug Administration - FDA, 2011. Chapter 10. Disponível em: <http://www.fda.gov/ Food/FoodScienceResearch/Laboratory Methods/ucm071400.htm>. Acesso em: 27 jul. 2015.

KORNACKI, J. L.; JOHNSON, J. L.
Enterobacteriaceae, coliforms, and Escherichia coli as quality and safety indicators In: DOWNES, F. P.; ITO, K. Compendium of Methods for the Microbiological Examination of Foods. Washington, DC: American Public Health Association - APHA, 2001. p. 69-82.

KOUSTA, M. et al. Prevalence and sources of cheese contamination with pathogens at farm and processing levels. Food Control, v. 21, n. 6 , p. $805-815,2010$

LAMBERTZ, S. T. et al. Prevalence and level of Listeria monocytogenes in readyto-eat foods in Sweden 2010. International Journal of Food Microbiology, v. 160, n. 1, p. 24-31, 2012

LANCETTE, G. A.; BENNETT, R. W. Staphylococcus aureus and staphylococcal enterotoxins. In: DOWNES, F. P.; ITO, K. Compendium of Methods for the Microbiological Examination of Foods. Washington, DC: American Public Health Association APHA, 2001. p. 387-403.

LEITE JÚNIOR, B. R. C. et al. Qualidade microbiológica de alimentos de origem animal comercializados na região de Minas Gerais. Vértices, v. 15, n. 2, p. 49-59, 2013.

LOGUERCIO, A. P.; AlEiXo, J. A. G. Microbiologia de queijo tipo Minas Frescal produzido artesanalmente. Ciência Rural, v. 31, n. 6, p. 1063-1067, 2001.

LOMBARDI, E. C.; REZENDE, M. T. N. P. Qualidade microbiológica do leite e do queijo Minas frescal processados em duas fábricas de laticínios sob inspeção municipal em Uberlândia - MG. Veterinária Notícias, v. 20, n. 2 , p. 71-78, 2014.

MARTINS, E. S.; REIS, N. E. V. Determinação de Coliformes e Staphylococcus coagulase positiva em queijos Minas Frescal. 
Revista Brasileira de Tecnologia Agroindustrial, v. 6, n. 2, p. 842-851, 2012.

NASCIMENTO, M. S. et al. Applicability of bacteriocin producing Lactobacillus plantarum, Enterococcus faecium and Lactococcus lactis ssp. lactis as adjunct starter in Minas Frescal cheesemaking. International Journal of Dairy Technology, v. 61, n. 4, p. 352-357, 2008.

OKURA, M. H.; MARIN, J. M. Survey of Minas frescal cheese from Southwest Minas Gerais for virulence factors and antimicrobial resistance in Escherichia coli isolates. Ciência Rural, v. 44, n. 8, p. 1506-1511, 2014.

PINTO, F. G. S. et al. Qualidade microbiológica de queijo Minas Frescal comercializado no município de Santa Helena, PR, Brasil. Arquivos do Instituto Biológico, v. 78, n. 2, p. 191-198, 2011.

RIBEIRO, E. P. et al. Desenvolvimento de queijo Minas Frescal adicionado de Lactobacillus acidophilus produzido a partir de retentados de ultrafiltração. Ciência e Tecnologia de Alimentos, v. 29, n. 1, p. 19-23, 2009.

RODRIGUES, J. et al. Levantamento das características físico-químicas e microbiológicas de queijo Minas frescal e mussarela produzidos no entorno de Goiânia - GO. Revista da Universidade Vale do Rio Verde, v. 9, n. 1, p. 30-34, 2011.

RYSER, E. T.; DONNELLY, C. W. Listeria. In: DOWNES, F. P.; ITO, K. Compendium of Methods for the Microbiological Examination of Foods. Washington, DC: American Public Health Association - APHA, 2001. p. 343-353.

SAKUMA, A. M. et al. Procedimentos e determinações gerais. In: ZENEBON, O.;
PASCUET, N. S.; TIGLEA, P. Métodos físico-químicos para análise de alimentos. São Paulo: Instituto Adolfo Lutz, 2008. p. 83-160.

SALOTTI, B. M. et al. Qualidade microbiológica do queijo minas frescal comercializado no município de Jaboticabal, SP, Brasil. Arquivos do Instituto Biológico, v. 73, n. 2, p. 171-175, 2006.

SANTANA, E. H. W. et al. Estafilococos em alimentos. Arquivos do Instituto Biológico, v. 77, n. 3, p. 545-554, 2010.

SENGER, A. E. V.; BIZANI, D. Pesquisa de Staphylococcus aureus em queijo Minas Frescal, produzido de forma artesanal e industrial, comercializado na cidade de Canoas/ RS, Brasil. Revista de Ciências Ambientais, v. 5, n. 2, p. 25-42, 2011.

SILVA, F. T. Queijo Minas Frescal. Brasília: Embrapa Informação Tecnológica, 2005. 50p.

VISOTTO, R. G. et al. Queijo Minas Frescal: perfil higiênico-sanitário e avaliação da rotulagem. Revista Instituto Adolfo Lutz, v. 70, n. 1, p. 8-15, 2011.

WOLUPECK, H. L. et al. Evolução da qualidade microbiológica de queijo Minas frescal comercializado em Curitiba (PR) no intervalo de 10 anos (1999 e 2009). Revista Acadêmica: Ciências Agrárias e Ambientais, v. 10, n. 3, p. 243-252, 2012.

WONG, A. C. L.; BERGDOLL, M. S. Staphylococcal food poisoning. In: CLIVER, D. O.; RIEMANN, H. P. Foodborne Diseases. Amsterdam: Academic Press, 2002. p. 231 248.

ZONTA, G. et al. Qualidade Microbiológica de Produtos Cárneos e Lácteos Comercializados em Feiras Livres de Arapongas-PR. Unopar Científica: Ciências Biológicas e da Saúde, v. 15, n. esp., p. 377-383, 2013. 